\title{
Compás de apertura. David Bowie en tres textos de Jorge Díaz, José Donoso y Roberto Bolaño*
}

\author{
Compass opening. David Bowie in three texts by Jorge Díaz, \\ José Donoso and Roberto Bolaño
}

Sergio Aliaga Araneda**

\begin{abstract}
RESUMEN
La madeja de este ensayo es David Bowie, como un motor o siquiera una excusa. Tomándome de su figura, su obra, y sus finitos quehaceres, devano tres hilos, a saber, el de Jorge Díaz, José Donoso seguido por Roberto Bolaño, donde cada uno absorberá la estela del cantautor, invocándole para evidenciar divergencia ("Todas las fiestas del mañana" [escrito en 1981, pero publicado en 2013]), extrañeza (El jardín de al lado [1980]) o aprehensión (Consejos de un discípulo de Morrison a un fanático de Joyce [1983]) frente a un escenario marcado por el exilio. En función de lo dicho, constato cómo la figura, la música e inclusive la lectura de Bowie, marca tres escenas pertenecientes a los fatídicos años 80 , en los cuales, el exilio asoma como una experiencia a desgranar cual compás de apertura.
\end{abstract}

\section{SUMMARY}

David Bowie is threaded through this essay, as a driver or even an excuse. I look at the person, his work, and his profession, and unravel three threads, namely, of Jorge Díaz, José Donoso and Roberto Bolaño, where each one will absorb the singer-songwriter's aura, invoking him to show divergence ("Todos las fiestas del mañana") (In English: All Tomorrow's Parties) "[written in 1981, but published in 2013]), strangeness (El jardín de al lado) (In
Palabras clave:

David Bowie, Jorge Díaz, José Donoso, Roberto Bolaño, exilio.

Keywords: David Bowie, Jorge Díaz, José Donoso, Roberto Bolaño, exile.

\footnotetext{
* Este artículo se inscribe en el Proyecto Fondecyt Regular $\mathrm{N}^{\circ} \mathrm{N}^{\circ} 1201369$, titulado Comunidades de la violencia: lecturas restitutivas de las dramaturgias chilenas de cien años, cuyo investigador responsable es el Dr. Cristián Opazo Retamal y del cual figuro en calidad de tesista. Por otra parte, agradezco los oportunos comentarios del Dr. Pablo Chiuminatto y la Dra. Rubí Carreño Bolívar durante el desarrollo de este trabajo.

** Chileno. Licenciado en Letras Hispánicas de la Pontificia Universidad Católica de Chile, PUC. Estudiante de Magíster en Literatura de la PUC. sealiaga@uc.cl
} 
English: The Garden Next Door) [1980]) or apprehension (Consejos de un discípulo de Morrison a un fanático de Joyce) (In English: Advice from a Morrison disciple to a Joyce fan) [1983]) in a scenario of exile. Based on what has been said, I note how the figure, the music and even the reading of Bowie, mark three scenes pertaining to the fateful 80 s, in which exile appears as an experience to deconstruct any compass opening. 


\section{Introducción}

Santiago, 2016. Estación de Metro Los Héroes: Łos We can be Heroes (Fig. 1). Con cierta nostalgia, la intervención destaca el fallecimiento de David Robert Jones, conocido mundialmente como David Bowie (1947 - 2016). Quien fuera músico, compositor, actor, productor e incluso diseñador de modas, regaría lágrimas por el suelo patrio, dejando, entre otras cosas, manifestaciones como aquella. Natalia, profesora de inglés, artífice de la intervención, pega la proclama justo ante de ser advertida por los funcionarios de metro. Porque nada podrá vencernos, seremos héroes hasta el final. ¡Amén!

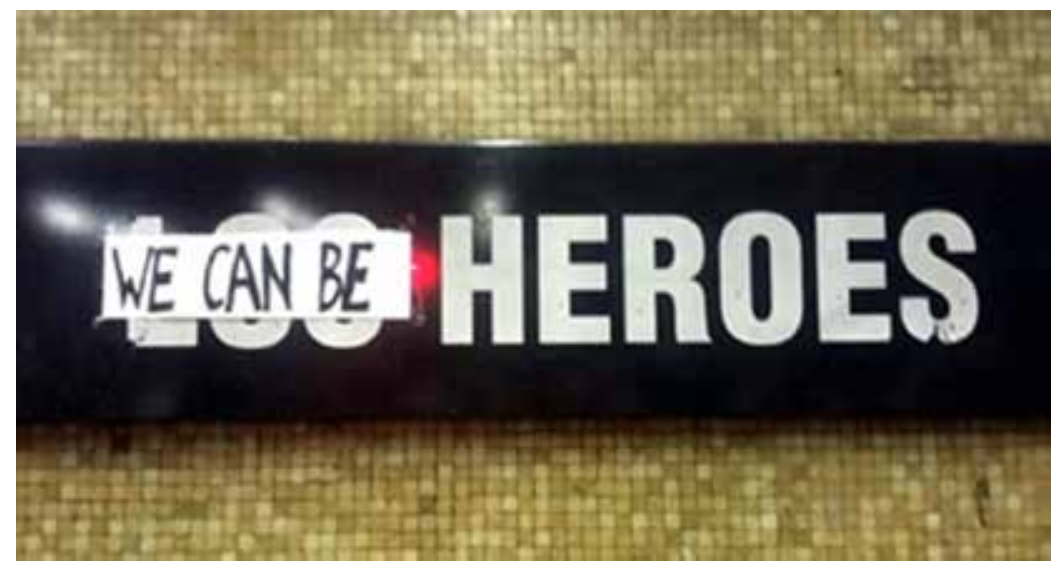

Fig. 1: "We can be heroes”. Imagen digital. Paniko.cl. Edit. Alejandro Jofré, 2016. Web. Revisado 02 de diciembre del 2020. https://paniko.cl/david-bowie-en-elmetro-de-santiago/

Homenajes como este se repetirían en diversas colinas del mundo. Más aún. En visión del académico de la Sheffield Hallam University, Jack Black (211), la prensa, redes digitales o público masivo, reaccionaría de tal modo ante la muerte del británico que este significaría, pese a quien pese, apenas un fetiche de orden teatral. Esto último, por supuesto, no sería, en ningún caso, una afrenta contra el músico; al contrario, en glosa de Simon Reynolds (2016), Bowie, como varios otros artistas del glam rock (Marc Bolan, Alice Cooper, The New York Dolls), fagocitaría dicho precepto. "[El glam] puso un contraste total con el estilo pesado que le había precedido: contra el rock de ejecución brillante y vestuario discreto, hizo estallar un exceso de imagen que precedía al propio rock" (15). De ahí que, como cantase Bowie en "Fashion", 
haya, con el glam rock, un nuevo lenguaje, el cual, se escucha casi tanto como se ve. Bowiefilia, como la resume Mariana Enriquez (634), en la que la divergencia se entrecruza bajo la farola del glam. Claramente semejante hipótesis podría discutirse, pues Bowie, a lo largo de su vasta carrera, incursionará en un abanico de géneros tales como el folk con matices psicodélicos (el homónimo David Bowie [1967] o Space Oddity [1969]), pasando por el soul (Young Americans [1975]), hasta la electrónica experimental (piénsese en la trilogía integrada por Low [1977], Heroes [1977] seguido por Lodger [1979]), entre tantísimos otros.

Luego de este breve examen, cabe preguntarnos, de manera homologa, por Bowie y las animadas respuestas que su muerte generase en Chile. Puesto que, ¿ icuán amplia es la influencia de Bowie en nuestro país? Imposible de responder. Amplísima. Corrijo: ¿cuán cercana es la figura del músicos a las artes y humanidades en estas tierras? Un poco menos amplia, pero aun así material de tesis ${ }^{1}$. Una vez más: ¿cuán próximo es Bowie a las letras chilenas? Bien. Como dijera Josefina Ludmer (Dalmaroni 9), mi campo es el de la literatura. De ahí sin más trataré de responder, cruzando, cuando la ocasión así lo amerite, hacia el vasto territorio de la música pop.

Veamos. El fallecimiento de Bowie azotó casi indistintamente a los escritores, periodistas o académicos en Chile. Se escribieron epitafios, se llenaron revistas, se realizaron homenajes como el de la antes mencionada profesora Natalia. Entre las muestras más notables está la de Rafael Gumucio, quien, desde las páginas de El Mercurio Blogs (s/p), dedicara una brevísima crónica - titulada "Lázaro" - en donde hila una genealogía entre Bowie y referentes literarios de alta diversidad, orillando la narrativa de Joseph Conrad, hasta Marc Bolan acompañado de Bob Dylan, para, finalmente, retornar a Chile donde Bowie - asevera Gumucio- jamás hubiese existido. Otro homenaje en la

$1 \quad$ Una de las últimas tesis dedicadas al compositor, es la de Cristóbal de Ferrari: "El arte musical de David Bowie en la lengua de Theodor Adorno" (2020). En esta, el candidato a Doctor en Filosofía por la Universidad de Chile, toma las consideraciones de Adorno respecto de la teoría musical para, en un gesto apropiativo, acercarlas a la música de Bowie. Entre las conclusiones, sugiere que en la música del británico habita un algo torcido (216) que, dada sus capas, nunca se termina de escuchar del todo. Repitiéndose, canción tras canción. Es el sujeto estirado, cual rizo, que siempre retorna hacía sí mismo. Agradezco a Cristóbal de Ferrari - así como a mi profesora María Inés Zaldívar por ponernos en contacto- en la prestación de su tesis, por ahora inédita. 
misma línea fue el que dio origen a Cuentos para Bowie (2017), sentido muestrario con el cual un grupo de escritores (Bruno Lloret, Matías Correa, Yosa Vidal Carmen Galdames, Claudio Aguilera, Natalia Berbelagua) se unió a un puñado de ilustradores (Carlos Garrido, Alexia Muñiz, Ángeles Vargas, Antonia Isaacson, Jorge Quien, Mariano Xerez) para exhumar el recuerdo del artista mediante el arrebato de algunas de sus canciones más emblemáticas: "Space Oddity”, “Starman", “Lazarus", entre otras.

Aunque lo cierto es que la presencia de Bowie en la literatura chilena figura anterior a su, digámoslo ahora, prematura muerte. Un afán particularmente quisquilloso notaría que la imagen del música yace cómoda en ciertas novelas de los $80 . . .90$. Hebra precursora, en ese sentido, es el proyecto de investigación, llevado a cabo por Cristián Opazo (2013), en torno a las narrativas de Augusto D'Halmar, José Donoso a la par de Alberto Fuguet, donde Bowie aparecerá en la sección dedicada a Donoso: el uso de anglicismos tales como kook (gay), Donoso lo toma desde Bowie (más precisamente de la canción homónima: "Kooks"), haciendo de su escritura un lenguaje errante cuya patología, en decir de Opazo (2), es la proliferación de giros excéntricos a la lengua española. Con prohijar (eufemismo para indicar el amancebamiento entre un adulto varón con un muchachito) o adrift (deriva, errante o errado) para el caso de D'Halmar y Fuguet, respectivamente.

Como he querido demostrar, Bowie, en relación con las letras chilenas, emula múltiples senderos. Por ahora, me detendré en tres casos en suma particulares, estos son, el de Jorge Díaz (1930 - 2007), el ya enunciado José Donoso (1924 - 1996) e incluyo, al último, a Roberto Bolaño (1953 - 2003). Estos escritores -dramaturgos, poetas, cuentistas- invocan la figura del músico para datar su exilio o extranjería, dado que, si Díaz toma la rabiosa nostalgia de Bowie (Lou Reed, Brian Ferry \& asociados) para encumbrar a los jóvenes de la Movida madrileña (c. 1980), en su inédito “Todas las fiestas del mañana” (2017); Donoso hará lo suyo con El jardín de al lado (1981) cuando exalte al Bowie setentero en aquella novela ambientada en Madrid; también Bolaño recurrirá al llamado ídolo del glitter (Copetas 182) tanto en su mítico encarcelamiento en un cruce de Los Ángeles (c. 1973) así como sus primeras publicaciones (Consejos de un discípulo de Morrison a un fanático de Joyce de 1984, entre otras). En retrospectiva, mi trabajo plantea cómo 
la figura de David Bowie surge, en estas escrituras, para evidenciar ya sea (auto)exilio, extrañeza o aprehensión. Tres cartas para Bowie, un homenaje desde Chile donde el músico marcará las coordenadas para un pronto contacto entre respectivos escritores.

\section{Díaz en Madrid Marte}

1970. Jorge Díaz, desde las páginas de Latin American Theatre Review, deja su renuncia ${ }^{2}$, pues cansado del lúgubre ambiente cultural de los 50 a los 70 en Chile, parte a un denominado autoexilio, integrándose a compañías itinerantes en donde escribirá un gran (y poco estudiado) número de obras. Los años posteriores a aquel exilio resultan especialmente productivos, puesto que, un Díaz desconocido para el público de ese entonces comienza a gestarse: los 80 , por ejemplo, encuentran a un Díaz instalado en Madrid, donde, desde aquel ademán voluntario -vista privilegiada, por otra parte, a los cruentos años de la dictadura chilena (c. 1973 - 1990)- se encandilará por los efectos previos a la Movida Madrileña, aquel fenómeno en plenos ochenta, en el cual, la subcultura juvenil glorifica, en extremo, un presente casi perpetuo, sin mirar hacia el pasado, sin garantías de un futuro ${ }^{3}$. Díaz, motivado por ese aspecto, recogerá su propia mirada en "Todas las fiestas del mañana”, escrito en 1983 aunque publicado, en Ediciones UC, en el 2013. Título tomado al pie del álbum The Velvet Underground \& Nico (1967), canción: “All Tomorrow's Parties". Cristián Opazo, uno de los encargados de la publicación de este texto, escribe a propósito del Díaz madrileño:

2 El breve "Dos comunicaciones" (1970) de Díaz es un alegato contra el teatro universitario de aquella época (c. 1941-1973). En relación con el elenco de Teatro ICTUS, Díaz decide abandonar Chile en 1967, dado que "todas las formas usuales del lenguaje [teatral] se me han ido desinflando, cayendo por el camino. En lenguaje costumbrista, el lenguaje como expresión psicologista [sic.], las formas más o menos habituales del lenguaje coloquial, el lenguaje culto de exposición de idea, etc., se han ido convirtiendo para mí en fórmulas vacías" (75). Una cuestión atañida a la Lengua con mayúsculas, o vana minúscula.

3 La Movida madrileña. Conjunto de manifestaciones de tipo juvenil —durante la década de los ochenta - que, en palabras de Héctor Fouce (273), responden a una suerte de hibridación cultural, o bien, una reacción a dos puertas entre la sociedad franquista y la nueva camino a la democracia. Espacio archicolorido entre ambas posturas. Estos jóvenes, fascinados por las creaciones del Reino Unido (especialmente por quienes se oponen al gobierno de Margaret Thatcher), e igualmente descreídos acerca de las dicotomía clásica hetero-homo sexual, alentaron la mezcla extravagante en las artes, en la vida misma (Opazo, "obreros, polizontes, pupilos..." 41). 
¿Por qué publicar una obra que el propio autor desdeña [como menor]? Treinta años después, Todas las fiestas del mañana encuentra su momento de legibilidad. Aquello que ayer deslumbró como ademán pasajero (el vocabulario ajeno, extraño, chocante de los parroquianos de la Rock Ola), hoy día se oye como una proclama desbordada por la urgencia de los afectos: aquí los adolescentes que reclaman soberanía sobre sus propios cuerpos; aquí los adolescentes que despliegan la inmensidad de sus deseos. All Tomorrow's Parties: quizá, el título musical de este manuscrito olvidado sea, para Jorge Díaz y sus lectores, el anuncio profético de una celebración que nunca llegó (35, las cursivas son de él).

Tal vez la mejor manera de describir la hazaña de Díaz sea recurriendo al Bowie de los 70. En 1971 lanza Hunky Dory, álbum cuasi legendario donde canciones como "Changes", "Oh! You Pretty Things" o "Queen Bitch" incentivan el cambio hacia una nueva época, cargada de ambigüedad tanto sexual como creativa. No sería descabellado, en ese sentido, imaginar a Díaz quien igual que la protagonista de la canción “Life on Mars?": muchacha de pelos rizados va al cine, y, durante la película (aburridísima: ¡ella ha vivido mucho más!), fantasea con la vida en Marte. Freak Show, canta Bowie. Símil a Jorge Díaz; un señor con ademanes casi marcianos que, cansado de su planeta natal, escribe desde una nueva localidad, desde un novedoso lenguaje. Chile en virtud de Madrid, o Madrid en miras a Marte. Los personajes de "Todas las fiestas del mañana" —en orden de aparición: Missa (yonqui con arrebatos punk), Chema (prostituto gay en busca de clientela), $\mathrm{Cu}$ rro (trajeado con camisa y corbata rosa, en espera de su novia), Paco (gigoló interesado en mujeres mayores), Elisa (en sus cuarenta, pintarrajeada), Moncho (dealer de Missa), el camarero (quizá el menos estrambótico) - hablan como los jóvenes pertenecientes a la Movida. Rocambolescos giros cuya derivación recae en palabras tales como basca, chunga, chute, julandrón, retambufa o trullo. Tamaños epítetos requieren de un glosario, casi siempre a la mano (Opazo, "Madrid, Madrid..." 34).

Trama. Estamos en un bar "con pretensiones de pub" (Díaz 43). De fondo suena música disco. En el centro nuestros personajes bailotean desganados. Cada uno - como detallo en sus descripciones-, tiene distintos motivos para estar ahí, aunque todos coinciden en un mismo 
punto: la música (sea Bowie o Lou Reed) les identifica. Subrayo esa cuestión, pues se deben a ella para marcar su diferencia ante los demás, sea entre la propia Movida o la sociedad. Por ello, si así se quiere, la identidad se exhibe cual marca registrada. En una suerte de dime cómo te ves..., los personajes de "Todas las fiestas del mañana" sacan, al pie de la letra, sus trapitos al sol. Missa, por ejemplo, tararea una canción de The Velvet Underground titulada "Í'm waiting for the man" (parte del disco homónimo a la banda), donde, un presunto yonqui espera, con veinte dólares en la mano, a un dealer. En traducción del propio Díaz:

La cabeza me da vueltas

solo estoy buscando a un sucio amigo mío.

Estoy esperando a mi hombre.

Subes unos escalones oscuros

tres pisos arriba

todo el mundo te tiene fichada

pero a nadie le importa (56).

La música maneja a los personajes cual monigotes. “iMuérete de una sobredosis, maldito Lou Reed!” (49), grita Missa. O bien como dijese Curro: David Bowie es Dios (55). Cuestión de sensibilidad, más nunca de gusto. De identidad (por más cursi suene esta palabra, por más kitsch), pues, tal como Bowie en las fotografías de "Life on Mars" -producidas, en su momento, por el mítico Mick Rock (Taschen, 2020) - , los personajes de Díaz reclaman una mirada sobre sí, un gesto, una pose tras un fondo blanco. Una misma lengua casi alienígena para oídos castellanos. $\mathrm{O}$ en su defecto: "[s]in temor agorafóbico a desviarse de la lengua materna, Missa, Chema, Curro, Paco y Moncho intercambian parlamentos que asemejan poemas en prosa, reescrituras bastardas de himnos menores del punk y la new wave" (Opazo, "Agorafobia.." 41).

La gente mira el maquillaje sobre su cara, riéndose de su pelo oscuro. Canta Bowie en "Lady Stardust", parte de The Rise and Fall of Ziggy Stardust and the Spider from Mars (1972); entregándonos de cierta manera pistas para leer, o inclusive comprender, el texto de Díaz: lo importante cabe a ojos del espectador. Una mirada que marca su diferencia a ras de estrambótico erotismo. Así, mientras en Chile visten alegorías para evitar la censura (piénsese en toda la Escena de Avanza- 
da), Jorge Díaz tiñe sus escritos de mostacilla barata. Lector del inglés Joe Orton (Entertaining Mr. Sloane, 1964), los franceses Jean Poiret ( $L a$ Cage aux folles, 1973) y Bernard-Marie Koltés (La Nuit juste avant les forêts, 1976), con David Bowie a la cola ${ }^{4}$. Espíritu glam, cuánto menos.

\section{Donoso, un Rimbaud empaquetado}

José Donoso era un entusiasta viajero. En su juventud, viajó a la Universidad de Princeton para estudiar, convidado por una Beca de la Doherty Foundation (c. 1949), un bachiller en Letras inglesas. En aquel periplo publicaría - bajo la revista MSS (la cual contó con apenas tres ediciones) - dos cuentos: "The blue woman" así como un tal "The poisoned pastries" (ambos de 1950). Volvería a Chile en 1954, donde, entre otros quehaceres - detallados en su Historia personal del boom (1972)_, publicaría una primera novela: Coronación (1955). En años posteriores viajaría frecuentemente a algunas países aledaños como México o Buenos Aires. En 1967 (mismo año en que Jorge Díaz parte al exilio), se trasladaría a España, permaneciendo allí hasta 1981, debido, en parte, a las trágicas consecuencias del Golpe de Estado (1973). Una vez en Chile, Donoso haría todo lo humanamente posible para encumbrar un legado: dictaría un taller cuya inspiración serían los promovidos en tierra estadunidense (el Writer's Workshop de la Universidad de Iowa), obtendría el Premio Nacional de Literatura (c. 1990) o asimismo blandiría sus raíces genealógicas - el primer Donoso fue hijo de un cura durante la Colonia, dice en Conjeturas sobre la memoria de mi tribu (1996) - . Ya en su lecho de muerte, pediría, como último gesto, le leyesen Altazor (1931)... En paracaídas hacia el abismo.

Cuesta imaginar al Donoso trotamundos de los años 50. Como bien lo ha descrito Antonio Díaz Oliva (s/p), ese Donoso parece cercano a un tabú, ya que, desde aquel joven despierto, camino a la figura tan decadente de los últimos años, ¿cuántos pasos hay? Muchísimos. Tantos

4 Contrario a lo que se supondría, Jorge Díaz era un lector bastante omnívoro. Un recuento de su biblioteca - donada, en el 2017, a la Facultad de Letras UC- muestra cómo el dramaturgo acumulaba diversas clases de libros. Biografías varias, así como las letras de The Beatles o Lou Reed, por no olvidar, desde luego, a David Bowie o a los ya citados Orton, Poiret, Koltés y compañía. Véase en detalle en el siguiente link: https://bibliotecas.uc.cl/index.php?option=com_content\&view=article\&id=1433:ganadores-delconcurso-alianza-ediciones-uc-y-bibliotecas-uc\&catid=42:noticias-inicio\&Itemid= 123 
como partituras por el mundo. Pues Donoso, quien aseguraba a sus entrevistadores (Permanyer s/p) deleitarse con la música de Schubert, Chopin, Schuman, Liszt, Brahms o música de cámara, también era un atento escucha de David Bowie. Aunque no sin cierta extrañeza. Buen ejemplo yace en las páginas de El jardín de al lado, tal como me propongo desentrañar a continuación.

La trama es sencilla (no así sus múltiples capas). Julio Méndez protagonista, escritor exiliado-, junto a su esposa Gloria, cuida la casa del pintor Pancho Salvatierra (amigo e ingenuo simpatizante de la dictadura chilena) durante un verano en Madrid. Instalado en pos de ese ademán, se obsesiona con el jardín de su vecina, la Condesa De Pinell De Bray (o la condesita, como la llama). Esta última se pasea desnuda entre fiesta y piscinazo, provocando la mirada de Méndez. ¡Senda distracción! Ya que Méndez ha decidido ocupar la estancia en favor de una novela que viene escribiendo hace ya un tiempo; aunque bien, pareciera que los momentos a solas con su trabajo son mera excusa para espiar - como el fotógrafo de Rear Window (Hitchcock 1954), en palabras de Grínor Rojo (34) - a la condesita. Ahora, cuando finalmente termina su novela, el resultado peca desabrido. No le hace justicia a la condesa. Menos aún. La única lectora que aprecia, casi a regañadientes, su obra es Gloria, pues ni la imponente Nuria Monclús - editora, con resabios a Carmen Balcells-, o mucho menos la juventud (Pato, hijo del matrimonio Méndez, admite sin tapujos el hartazgo respecto de la dictadura) ven en ella un mínimo talante literario. Reacción similar a la de Bijou, ángel multiforme...

\section{¿Quién es Bijou?}

Si Missa en compañía de Curro, Paco y Moncho teñían el texto de Díaz con los colores de la Movida, el personaje de Bijou lo hará en la novela de Donoso. Situación onírica para el protagonista; puesto que, pese a sentir una clara fascinación por el joven, recurrirá a tupidas muestras para demostrar que lo suyo no es sino "un deseo de apropiarme de su cuerpo, de ser él, de adjudicarme sus códigos y apetitos, mi hambre por meterme dentro de la piel de Bijou era mi deseo porque mi dolor fuera otro" (84). Dolor atañido, por lo demás, a las consecuencias de la dictadura chilena. La madre de Méndez - la otra cara del jardín: el de la infancia- agoniza lentamente en Chile, de modo que, un púber rapado sin angustia por la historia pasada o actual, junto a un 
cincuentón cargado de fantasmas no hacen, bajo ninguna perspectiva, buena pareja. De tal manera el contraste entre Julio Méndez y Bijou lo pondrá David Bowie.

Durante uno de los primeros encuentros con Bijou (aunque, en realidad, Méndez desconoce su nombre), el novelista confiesa a su amigo Carlos Minelbaum, médico exiliado, la extrañeza que le produce el andrógino. Le gustaría, según dice, que él lo quisiera como no lo hace su propio hijo, comparándolo incluso con un ángel musicante (77). Así sin más, en ese preciso instante, lo invoca. Cual ángel de la historia (Benjamin 310), Bijou llega para marcar su pronta tempestad, dado que, tal como detallase la letra "Kooks" de Bowie (copiada por Donoso en la novela):

If you stay

won't be sorry

'cause we believe in you...

Soon you'll grow

so take a chance

with a couple of kooks...

...

We've got

a lot of things

to keep you warm and dry

and a funny old crib

on which the paint won't dry... (Donoso, El jardin... 89-90, cursivas del original).

Si te quedas

no te arrepentirás

porque creemos en ti...

pronto crecerás

así que da una oportunidad

a este par de locos...

Tenemos

un montón de cosas

que te mantendrán cálido y seco

una vieja y divertida cuna

en la que la pintura no se seca... (la traducción es mía). 
En la novela, los versos son transcritos en su lengua original, el inglés, marginando, con ese gesto, a posibles lectores no letrados. Asimismo, en la copia, el transcriptor olvida un único verso: hung un romancing. Colgados en un romance. Corta la canción sin más dado que, como ya indiqué, lo satisfactorio no es un posible escarceo con Bijou (nombre que, por lo demás, se traduce como joya desde el francés, es decir, otro gesto velado por cierta clase de multilingüismo); al contrario, Méndez busca ser Bijou, apropiarse de sus códigos, de su vestimenta, de su libertad. El contraste resulta notorio. Entre Méndez y Bijou existen años luz de diferencia, por eso Méndez, para describirlo, recurre a códigos pertenecientes a un lenguaje culto, pomposo. “Rimbaud! ¡Ya me parecía haber conocido la malvada suciedad rubia, el desafió perverso de los ojos claros los inmundos dientes defectuosos del personaje de Coin de table!" (78). De esa manera "Kooks", tanto la canción como el anglicismo, no está en su vocabulario. Esa complicidad con Bijou, o con los jóvenes de la Movida, jamás la obtiene. Menos aún. Méndez actúa como un quinceañero inseguro buena parte de la novela, por ello, es incapaz de abandonar su pasado político, o siquiera rendir tributo a su madre enferma. Todo lo consume, así, tan pronto crezca - canta la canción de Bowie- encontrará una oportunidad. Tan pronto abandone aquel sueño de escribir la gran novela del boom, la novela de la dictadura chilena. Fracaso estrepitoso.

Si Méndez, espejo cóncavo a José Donoso (Rojo 43), obrase como Díaz en “Todas las fiestas del mañana”, entregándose a la manifestaciones de la Movida, tal vez - y solo tal vez - hubiera obtenido un mejor pasar. No fue el caso. Méndez acaba sus días enseñando literatura en alguna universidad de Europa, mientras Gloria - práctica conocedora de astrología; cercana a la juventud, a las discotecas- escribe la novela, esa misma que ahora yace en nuestras manos. Las mil máscaras de una escritura (Morales 86-87), o de este Rimbaud empaquetado tras el nombre de Julio, Gloria Méndez o ¿José Donoso? Don't dream it. Be it. Canta el Dr. Frank N' Furter a finales del musical The Rocky Horror Picture Show (Sharman 1975), influencia importante para el glam y para David Bowie. Eco a José Donoso, a toda una genealogía. 


\section{Coordenadas R. B. ${ }^{5}$}

\section{Trataré con Roberto Bolaño.}

Dicho eso, tacho su nombre a lo largo de este apartado, quedándome tan solo con sus iniciales: R. B, cual coordenadas de un meteoro que atraviesa el cielo abierto de América. Huella que, sin duda, habrá de perdurar. Resume impecable Jaime Concha (343)—, pues R. B. no es sino eso: un meteorito, visto que incluso la crítica lo trata de semejante manera. Títulos como Territorios en fuga: estudios críticos sobre la obra de Roberto Bolaño (2003). Roberto Bolaño: una literatura infinita (2004). Bolaño salvaje (2005). Pistas de un naufragio. Cartografía de Roberto Bolaño (2009). Roberto Bolaño: otra vuelta de tuerca (2010). Roberto Bolaño: la experiencia del abismo (2011). Bolaño traducido: nueva literatura mundial (2011). Roberto Bolaño. Estrella cercana (2013). Roberto Bolaño: el investigador desvelado (2015). Bolaño Constelaciones (2020), entre otros ${ }^{6}$, vienen sino a atestiguar tal certeza.

Como se aprecia por sus títulos, la gran mayoría alude a dimensiones inaprehensibles, o majestuosas hazañas, ya que, la escritura de $\mathrm{R}$. B. - coteja nuevamente Concha (354) — resulta de una tensión elástica in extremo. Superficies que se entrelazan unas con otras, como es el caso de La literatura nazi en América (1996) con aquel árbol genealógico en siembra del horror (Mercier y Rocco 188-189), o 2666 (2004) frente a esa estructura cuyos límites son sino abis(m)ales (Moreno 21). Sobran ejemplos... Complejo dinamismo. Ahora, ¿dónde encontrar "un vacío potencial para todas las configuraciones que se sucederán en macroescala" (Concha 354) en la escritura de R. B.? ¿Dónde está aquel afán cósmico tan enunciado por la crítica? O mejor dicho: ¿dónde ubi-

5 Un primer esbozo respecto de este apartado fue escrito para el curso de "Narrativa Hispanoamericana", versión Magíster en Literatura, a cargo de la Dra. Macarena Areco. En este, encumbraba un recorrido por la narrativa de R. B. en busca de un supuesto alunizaje espacial. La luna aparece en cada uno de los libros de R. B., jen todos!, no como mero adorno, sino más bien como un ente que actúa por sobre las acciones de los personajes o la escritura. El presente apartado es una versión renovada de susodicho trabajo, pues, en ese entonces, David Bowie no formaba parte de él. Agradezco a la profesora Areco sus valiosos comentarios durante aquel recorrido.

$6 \quad$ Agréguense a esta lista algunos estudios en otras lenguas. Como Roberto Bolaño's Fiction: An expanding universe (2014; reeditado por Ediciones UDP el 2018), o Beyond Bolaño: The Global Latin American novel (2015; a la par reeditado por Crítica en 2020). Claro está: faltarían artículos, ponencias e incluso congresos dedicados a la obra o figura del autor. Aunque por ahora basta con dichas monografías. 
car apenas un ápice, minúsculo bosón, de aquel universo en continua expansión? En busca de una respuesta: en David Bowie.

Ocurrido el golpe de Estado en Chile, R. B. se haya en México con 20 años recién cumplidos. Cuando escucha la noticia decide, en un acto mítico y quizá estigmatizado, levantar armas y apoyar, como se pueda, a los caídos por el Golpe. Viajará a dedo en camiones o barcos, con paradas en Nicaragua, Costa Rica, Panamá, enviando, cada cierto tiempo, cartas a sus familiares. Una vez en Chile, será detenido en un cruce de Los Ángeles camino a Concepción, Región del Biobío. Confinado en una celda por alrededor de ocho días (la cantidad cambia según quién cuente la historia) escribirá un poema:

Era sobre David Bowie y Nueva York. Lo escribí mientras estuve detenido y era un poema muy malo pero mejor que todo lo que hacía por aquella época que era horrible. Durante ese período sólo me ocurrieron dos cosas: el poema de Bowie y leer, también estando preso, un reportaje sobre la casa de campo de Dylan Thomas, en Gales. Me impresionó porque jamás pensé que Dylan Thomas tuviera una casa tan increíble y lujosa (citado en Rivera s/p.).

Un poema al que jamás obtendremos acceso. Un complejo vacío en la línea precursora a R. B. Ausencia que, sin embargo, amenaza como un hálito superviviente. Lo que no está en algún momento estuvo. "No habrá más que señales, singularidades, migajas, resplandores pasajeros e incluso débilmente luminosos" (Didi-Huberman 31-32), un corazón delator en toda su macabra gloria. En esa línea conjetural, fascina un poco la idea de R. B., encerrado en una celda, pensando en David Bowie. Quizá fantaseando con Space Oddity, cuyo single "Space Oddity", se lanza oficialmente en 1969. Mismo año del primer alunizaje espacial. En esta, un astronauta (Mayor Tom, o Comandante Tom por su traducción) deriva en el espacio sin comunicación con la Tierra. Está solo. Por ello, no sorprendería que R. B. hubiera escuchado más de una vez la canción, allí detenido. Esta dice: voy suspendido a bordo de una lata de aluminio. Lejos por encima de la luna. El Planeta tierra es azul y ya nada puedo hacer. Si el poema sobre Bowie no existe (para nosotros lectores), ¿dónde encontrar al menos un símil de aquel? Creo que en la poesía del autor. Tomemos por ejemplo "Mi vida en los tubos de supervivencia", recogido en Poesía reunida (2018), donde "un pigmeo amarillo" viaja, en una especie de nave espacial, buscando su destino. 
Me metieron en el interior de este platillo

Y me dijeron vuelta y encuentra tu destino, ¿pero qué

Destino iba a encontrar? La maldita nave parecía

El holandés errante por lo cielos del mundo (53)

$¿$ No parecen estos versos cercanos a las desventuras del Comandante Tom? Sería fácil decirlo; opto, no obstante, por la mesura. En una carta enviada a la crítica Soledad Bianchi, R. B., además de compartirle "Mi vida en los tubos de sobrevivencia" escribe: "el poema puede leerse como un cómic, una aventura pop en verso libre, pero también puede, y debe, leerse como un poema sobre la condición del poeta". Prontamente repara: "Por descontado, el texto tiene, aún, algunas lecturas más, y más interrogantes y enigmas, pero eso lo dejamos para otra carta". Fechada en febrero del 93, Blanes. Un cómic, una aventura pop en verso libre... Un guiño al buen humor. A ese poema nunca escrito con Bowie en la sesera?

Ahora, la metáfora espacial (tan enarbolada por la crítica) también surge en la narrativa. El póstumo Entre paréntesis (2004), reúne un brevísimo texto titulado "Palabras del espacio exterior", en el cual R. B. comenta las cintas captadas por algún ciudadano sin nombre durante el Golpe de Estado en Chile. En ellas, los altos mandos de la Fuerza Armada conversan, ríen e incluso temen prontas consecuencias:

En algún momento de nuestras vidas conocimos a quienes están hablando. Las voces, como si se tratara de una inmensa radionovela, están actuando para nosotros, pero sobre todo está actuando para ellos mismos. Pornografía, snuff movies. Por fin han encontrado el papel de su vida. Los soldados, finalmente, tienen su guerra, su mejor guerra: frente a ellos estamos nosotros, desarmados, pero mirando y escuchando (81).

Si el comandante Tom llamaba a la Tierra para enunciar su soledad en medio del vacío, R. B. emulará este juego frente al más ominoso de

7 Un antecedente. En un texto titulado oportunamente "Exilios" (datado en 1997), R. B. alude a su encierro en la Región del Biobío. Aunque en esta oportunidad, Bowie no saldrá a colación. "Durante ese tiempo, en lo que a la literatura respecta, sólo escribí un poema, no malo como los que solía escribir entonces, sino malísimo. Pasados [...] cinco meses volví a salir de Chile y nunca más he vuelto. [...] Ahí empieza el exilio o lo que se suele conocer como exilio, aunque la verdad es que yo no lo sentí así" (53). 
los peligros. La sangre corre en aval de la guerra. Infinito espacio el este mundo. Aunque eso no es todo, ya que, en ocasiones, las fechas coinciden como un manojo de estrellas. Brillan cual soles ennegrecidos, otorga Bowie en "The stars (are out tonight)", parte del último disco en vida Blackstar (2016). Obscura sincronía. Bien digo: si Díaz escribe "Todas las fiestas del mañana" a comienzos de los 80, o Donoso publica El jardín de al lado en 1981, R. B. escribirá Consejos de un discípulo de Morrison a un fanático de Joyce (a dos manos con A. G. Porta) el 83. Publicándoseluego de ganar el Premio Ámbito Literario- en 1984. No obstante, más allá de estas señas editoriales, ¿qué une la joven novela de R. B. con los textos de Díaz en comunión a Donoso? Adivinen: Bowie.

Justo después de un atraco, Ana Ríos en compañía de Ángel Ros descansan en un hotel. Esta pareja de ladrones resulta inusual: ella es violenta (de hecho, todas las muertes corren por cuenta suya), mientras él escribe... Delinque para escribir. "Observo a Ana como si estuviera a mi lado, me hubiera gustado nacer con esa sangre fría”, piensa ocioso. Sabe bien que no es tan valiente como Ana: por eso, tal como el Méndez de $E l$ jardín de al lado, en ocasiones le gustaría ser Ana. Escucha música. "El disco terminó, me levanté y metí en la ranura un par de monedas. Seleccioné y apreté los botones. David Bowie. En la mesa, Ana parecía hosca" (Consejos de... 10). Con Bowie de fondo aparece un par de policías. "Picoletos, anuncié. No te pongas nervioso, dijo ella. Creo que tengo taquicardia" (11). Nuevamente el mismo recurso: situar un contraste entre dos personajes con Bowie a la cabeza. Casi una alarma para estas situaciones. Ángel espera. "Comenzaba a aceptarme a mí mismo como una persona valiente cuando los guardias terminaron sus bebidas y se fueron". Fuera de peligro, Ángel se cree valiente. Ana, por el contrario "me miró sin sonreír" (13). El tiempo toma un cigarro para ponerlo en tu boca, canta Bowie en “Rock n' roll suicide”. Balada tónica para estos amantes.

Quede dicho. David Bowie aparece - canónicamente- solo una vez en las páginas de R. B. Por lo demás, en una novela compartida con A. G. Porta. Aun así asombra la sintonía entre R. B. a la estela de Bowie. Una llamada desde el espacio que se comunica con apenas dos letras, ya que si Díaz o Donoso invocaban a Bowie para simular extrañeza o exilio, R. B. también lo hará pero como un fantasma, un poema perdido. 


\section{Colofón ${ }^{8}$}

Santiago. Noviembre, 1997. Última visita de David Bowie a Chile. Court Central del Estadio Nacional: 3.500 asistentes. Cifra mínima. Entradas a 8000 galería, o 12.000 tribuna (Fig. 2). ¿Cuál de estas comprarían Díaz, Donoso o Roberto Bolaño de haber asistido? Quién sabe.

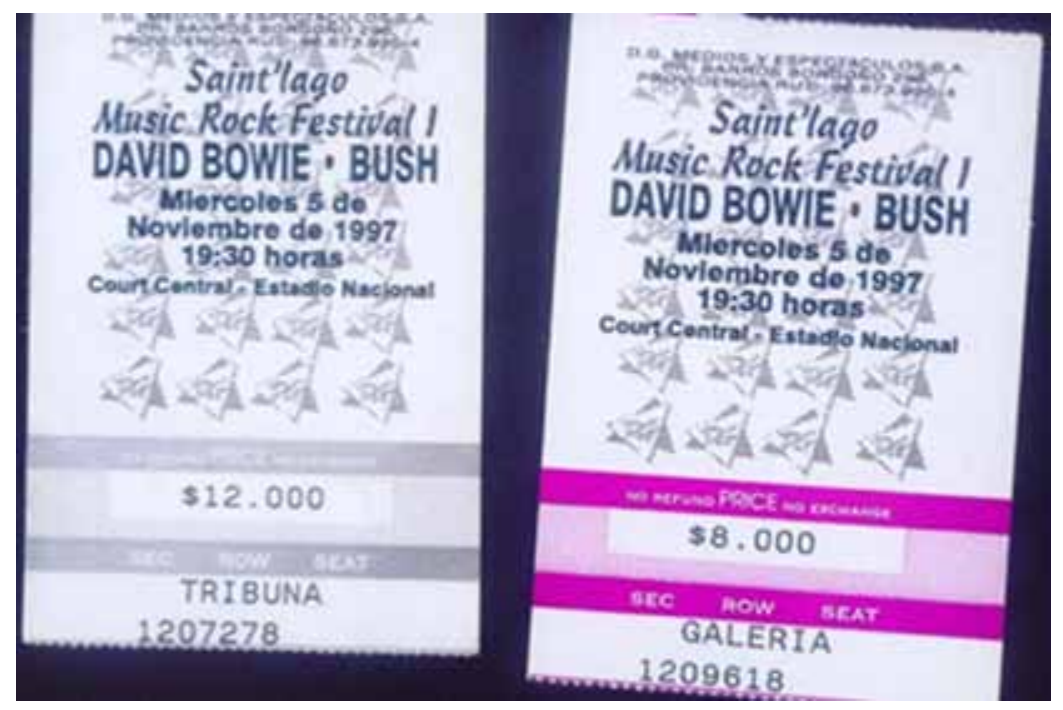

Fig. 2: "Bowie y su última vez en Chile". Imagen digital. Culto en La Tercera. Edit. Alejandro Tapia, 2017. Web. Revisado 14 de diciembre del 2020. https:// www.latercera.com/culto/2017/01/08/volver-al-futuro-bowie-ultima-vezchile/

A esa fecha, José Donoso había muerto hacía casi un año. Hace dos, Jorge Díaz había vuelto a Chile, donde fallecería en 2007, luego de vivir treinta años en España. Bolaño, en tanto, recién despegaba:

8 Una breve genealogía. Dentro de la tradición ensayística hispanoamericana, la voz colofón, esta es, la marca al final de un libro donde se detalla la fecha de publicación e imprenta, la utilizaba Alfonso Reyes para cerrar, cada tanto, sus ensayos de manera conclusiva. Este gesto, el del colofón, lo retomará Octavio Paz para refrentar sus propias publicaciones: ejemplar es el caso de El arco y la lira (1956), cuya primera edición Paz refrenta, mediante un colofón (“Los signos en rotación", 1967), en ediciones posteriores. Gesto que, además, tan solo en Chile, heredará el profesor Roberto Hozven, enseñándolo a su vez al crítico Rodrigo Cánovas, quien remplazará las conclusiones de sus artículos académicos con susodicho colofón. Asimismo, Cristián Opazo repetirá ocasionalmente el gesto. En rigor, el colofón viene a mostrar una apertura, un comentario adicional o dejo cronístico en remplazo de las conclusiones académicas. 
Los detectives salvajes se publicaría un año después, en 1999. Imagínenlo. Los tres quizá, pese incluso a sus marcadas diferencias biográficas o literarias, se hubieran entendido de estar en el mismo concierto. Por desgracia, esto no son más que conjeturas, pues, como he querido demostrar, lo importante - en cuanto a la relación de estos escritores-yace en los textos. Cada uno, desde un lugar similar, pero no así el mismo, conjura a David Bowie para significar divergencia, exilio o aprehensión como si se tratase de un fantasma, espíritu capaz de sintetizar una época, sea la Movida o el Madrid de los 80. Estos tres textos para, o en virtud de David Bowie arremeten silenciosos (recordemos que en su mayoría son obras menores dentro de cada uno de los abanicos autorales) una contra el otro. Dado que, solo de esa manera, escrituras tan disimiles son finalmente reunidas en una suerte de último concierto, donde Bowie oficia de maestro de ceremonias. Un compás de apertura.

\section{Referencias bibliográficas}

Benjamin, Walter. "Sobre el concepto de historia". Obras 1, Vol. II Trad. Alfredo Brotons Muñoz. Madrid: Abada, 2008, pp. 303-318.

Bolaño, Roberto. “Mi vida en los tubos de supervivencia”. Poesía reunida. Barcelona: Alfaguara, 2018, pp. 53-54. Impreso.

"El misterio transparente de José Donoso". Entre paréntesis. Barcelona: Editorial Anagrama, 2004, pp. 99-101. Impreso.

"Exilios". Entre paréntesis. Barcelona: Editorial Anagrama, 2004, pp. 49-58. Impreso.

"Palabras del espacio exterior". Entre paréntesis. Barcelona: Editorial Anagrama, 2004, pp. 79-81. Impreso.

"Sobre y carta de Roberto Bolaño a Soledad Bianchi [1993]". Cultura Digital UDP, 2017. Recuperado de: https://culturadigital.udp.cl/cms/index.php/coleccion/coleccion-robertobolano/documento/sobre-y-carta-de-roberto-bolano-asoledad-bianchi-7/

Bolaño, Roberto y Antoni García Porta. Consejos de un discípulo de Morrison a un fanático de Joyce. 1984. Santiago: Editorial Alfaguara, 2017. Impreso.

Bowie, David. Blackstar. Sony Records, 2016. CD.

Heroes. RCS Records, 1977. CD. 
Young Americans. RCA Records, 1975. CD.

. The Rise and Fall of Ziggy Stardust and the Spiders from Mars. RCA Records, 1972. CD.

. Hunky Dory. RCA Records, 1971. CD.

. Space Oddity. 1969. RCA Records, 1972. CD.

Black, Jack. "The reification of celebrity: global newspaper coverage of the death of David Bowie". International Review of Sociology 27.1 (2017): pp. 202-224. Recuperado de: https://www.tandfonline.com/doi/abs/10.1080/03906701.2016.1254393

Concha, Jaime. "Geometrías de Bolaño: observaciones sobre Amuleto". Leer a contraluz. Estudios narrativa chilena. Santiago de Chile: Ediciones Universidad Alberto Hurtado, 2011, pp. 341-353. Impreso.

Copetas, Craig. "El padrino del beat conoce al líder de la purpurina”. David Bowie. Memorias fotográficas a través de la lente de Terry $O^{\prime}$ Neill. Trad. Remedios Diéguez. Barcelona: Blume, 2019, pp. 180-193. Impreso.

Dalmaroni, Miguel Ángel. “Encuentro con Josefina Ludmer”. Orbis Tertius 4 (2000): pp. 1-22. Recuperado de: http://sedici.unlp. edu.ar/handle/10915/37701

De Ferrari Zaldívar, Cristóbal. "El arte musical de David Bowie en la lengua de Theodor Adorno". Tesis Universidad de Chile, 2020. Manuscrito inédito.

Díaz, Jorge. “Todas las fiestas del mañana”. Siete obras desconocidas de Jorge Díaz. Ed. María Teresa Salina Díaz. Santiago: Ediciones UC, 2013, pp. 41-57. Impreso.

“Dos comunicaciones". Latin American Theatre Review IV (1970): pp. 73-77. Impreso.

Díaz Oliva, Antonio. “A este lado del paraíso: José Donoso en Princeton". Latin American Literature Today, no. 16 (2020): s/p. Recuperado de: http://www.latinamericanliteraturetoday. org/es/2020/noviembre/este-lado-del-para\%C3\%ADsojos \% C $3 \%$ A 9 - don os o-en-princeton-de-antoniod\%C3\%ADaz-oliva

Didi-Huberman, Georges. Supervivencia de las luciérnagas. 2009. Trad. Juan Calatrava. Madrid: Abada editores, 2009. Impreso.

Donoso, José. El jardín de al lado. 1981. Santiago de Chile: Editorial Seix Barral, 1985. Impreso. 
Enriquez, Mariana. “Una extraña compañía”. El otro lado. Retratos, fetichismos, confesiones. Santiago: Ediciones UDP, 2020, pp. 633637. Impreso.

Fouce, Héctor. "La cultura juvenil como fenómeno dialógico: reflexiones en torno a la Movida Española". Cuadernos de Información y Comunicación. No. 5 (2000): pp. 267-275. Recuperado de: https://www.redalyc.org/pdf/935/93500515.pdf

Gumucio, Rafael, "Lázaro". El Mercurio Blogs [Santiago, Chile] 17 de enero del 2016, s.p. Web.

Mercier, Claire y Rocco, Bernardo. "Las develaciones genealógicas en Roberto Bolaño". Alpha $\mathrm{N}^{\circ} 45$ (2017): pp. 185-200. Recuperado de: https://scielo.conicyt.cl/pdf/alpha/n45/0718-2201alpha-45-00185.pdfMorales, Leónidas. "Máscara y enunciación". Novela chilena contemporánea: José Donoso y Diamela Eltit. Santiago: Editorial Cuarto propio, 2004, pp. 83-96. Impreso.

Moreno, Fernando. "En torno a una poética espacial en 2666". Orillas 6 (2017): pp. 19-28. Recuperado de: http://orillas.cab.unipd. it/orillas/articoli/numero_6/02Moreno_rumbos.pdf

Opazo, Cristián. "Agorafobia: crítica: universidad: claves para otra historia y crítica de la dramaturgia chilena". Aletria, vol. 26, no. 1 (2016): pp. 29-47. Recuperado de: http://www.periodicos. letras.ufmg.br/index.php/aletria/article/view/10049

"Obreros, polizontes, pupilos. Dramaturgias chilenas de cien años (notas en progreso)". Texto elaborado en el marco del proyecto FONDART 55388, 2015, pp. 3-72. Recuperado de: http://celich.cl/wp-content/uploads/2015/08/Obreros-polizontes-pupilos.pdf

"Madrid, Madrid: Todas las fiestas del mañana". En Jorge Díaz. Siete obras desconocidas de Jorge Díaz. Ed. María Teresa Salina Díaz. Santiago: Ediciones UC, 2013, pp. 29-35. Impreso.

"De armarios y bibliotecas: masculinidad, errancia y tradición letrada en las narrativas del siglo XX chileno (D’Halmar, Donoso, Fuguet)". Texto elaborado en el marco del proyecto Fondecyt 1110289, 2013, pp. 1-5. Recuperado de: http://repositorio.conicyt.cl/bitstream/handle/10533/203898/1110289. pdf? sequence $=1$ \&isAllowed $=y$ 
"De armarios y bibliotecas: masculinidad y tradición literaria chilena en la narrativa de Alberto Fuguet". Revista chilena de literatura. 74 (2009): pp. 79-98. Recuperado de: https://scielo.conicyt.cl/scielo.php?script=sci_arttext\&pid $=$ S0718-22952009000100004

Permanyer, Lluis. “Cuestionario Proust. José Donoso: navegante de tierra firme". La Vanguardia, 1979. Recuperado de: http://www. letras.mysite.com/jdon180618.html

Rear Window. Dir. Alfred Hitchcock. Paramount Pictures, 1954. DVD.

Reynolds, Simon. Como un golpe de rayo. El glam y su legado, de los setenta al siglo XXI. 2016. Trad. Hugo Salas. Buenos Aires: Caja Negra Editora, 2017.

Rivera, Angélica. “Tomo la literatura en broma”. Las Últimas Noticias [Santiago, Chile], 15 de noviembre de 1998. Web.

Rock, Mick. The rise of David Bowie. 2015. Eslovenia: Taschen, 2020.

Rojo, Grínor. "Donoso conversa con Donoso sobre la posibilidad de escribir la gran novela del golpe: El jardín de al lado". Las novelas de la dictadura y la postdictadura chilena. Quince ensayos críticos. Volumen II. Santiago: Editorial Lom, 2016, pp. 31-49. Impreso.

The Rocky Horror Picture Show. Dir. Jim Sharman. $20^{\text {th }}$ Century Fox, 1975. DVD. 